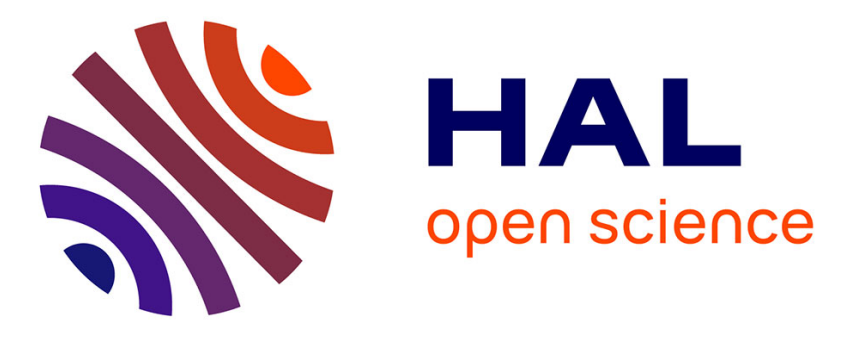

\title{
Synthesis of carbon nanotubes/hydroxyapatite composites using catalytic methane cracking
}

Bruna Rego de Vasconcelos, Ngoc Dung Tran, Doan Pham Minh, Ange

Nzihou, Patrick Sharrock

\section{- To cite this version:}

Bruna Rego de Vasconcelos, Ngoc Dung Tran, Doan Pham Minh, Ange Nzihou, Patrick Sharrock. Synthesis of carbon nanotubes/hydroxyapatite composites using catalytic methane cracking. Composite Interfaces , 2015, 22 (7), p. 673-687. 10.1080/09276440.2015.1060055 . hal-01609216

\section{HAL Id: hal-01609216 https://hal.science/hal-01609216}

Submitted on 20 Oct 2018

HAL is a multi-disciplinary open access archive for the deposit and dissemination of scientific research documents, whether they are published or not. The documents may come from teaching and research institutions in France or abroad, or from public or private research centers.
L'archive ouverte pluridisciplinaire HAL, est destinée au dépôt et à la diffusion de documents scientifiques de niveau recherche, publiés ou non, émanant des établissements d'enseignement et de recherche français ou étrangers, des laboratoires publics ou privés. 


\title{
Synthesis of carbon nanotubes/hydroxyapatite composites using catalytic methane cracking
}

\author{
Bruna Rêgo De Vasconcelos, Ngoc Dung Tran, Doan Pham Minh*, Ange Nzihou and \\ Patrick Sharrock
}

Centre RAPSODEE, Université de Toulouse, Mines Albi, CNRSUMR 5302, Albi, France

\begin{abstract}
Carbon nanotubes/hydroxyapatite composites (CNTs/Ca-HA) have been synthesized using catalytic methane cracking. This composite combines the advantageous properties of carbon nanotubes and hydroxyapatite. Carbon nanotubes (CNTs) have attracted increasing attention, thanks to their exceptional physical and chemical properties such as high tensile strength, small density and large length to diameter ratio, good chemical stability and high thermal and electrical conductivities. These properties render them attractive for applications such as reinforcements in various materials. Hydroxyapatite $\left(\mathrm{Ca}_{10}\left(\mathrm{PO}_{4}\right)_{6}(\mathrm{OH})_{2}, \mathrm{Ca}-\mathrm{HA}\right)$ is a versatile material which can be used in several applications: biomaterials, sorbents for heavy metal fixation from contaminated water, air and soil, catalyst supports. Catalytic methane cracking was carried out in a fixed-bed reactor wherein $\mathrm{CH}_{4}$ gas passed through a heated nickel-loaded $\mathrm{Ca}$-HA bed (Ni content: 5 wt.\%). The reaction significantly took place at $700{ }^{\circ} \mathrm{C}$ leading to the formation of CNTs. Reaction parameters such as temperature, methane flow rate and reaction time were investigated. The results presented propose a new approach for $\mathrm{CNT} / \mathrm{Ca}-\mathrm{HA}$ composite synthesis, in regard to the state of the art.
\end{abstract}

Keywords: composites; inorganic compounds; structured materials; surface growth; chemical synthesis; thermogravimetric analysis

\section{Introduction}

Carbon nanotubes (CNTs) have attracted increasing attention due to their exceptional physical and chemical properties, such as high tensile strength, small density and large length to diameter ratio, good chemical stability and high thermal and electrical conductivities.[1,2] Recent work has shown that CNTs are promising candidates for catalyst support in several reactions due to low diffusion resistance issues.[3] They showed improved catalytic activity in reactions such as hydrogenation of olefins, nitrobenzene into aniline, selective hydrogenation of $\mathrm{C}=\mathrm{C}$ bond in an $\alpha, \beta$-unsaturated aldehyde and selective catalytic oxidation of trace amounts of $\mathrm{H}_{2} \mathrm{~S}$ into elemental sulphur.[3,4] They also have been used for a wide range of applications such as alternative forms of energy production, energy storage and drug delivery.[5] Jiang et al. showed that CNTs can be used to make flexible devices for energy storage, which is important for applications in modern systems that demand components with adaptable shapes.[6] $\mathrm{Li}$ et al. proved that the presence of multi-walled carbon nanotubes (MWCNTs) in a

\footnotetext{
*Corresponding author. Email: doan.phamminh@mines-albi.fr
} 
nanocomposite made of stearic acid and MWCNTs improves the thermal conductivity of the stearic acid, which makes it a promising candidate for enhancing the heat transfer performance of energy storage systems.[7]

Hydroxyapatite $\left[\mathrm{Ca}_{10}\left(\mathrm{PO}_{4}\right)_{6}(\mathrm{OH})_{2}, \mathrm{Ca}-\mathrm{HA}\right]$ can be used in several applications, such as medicine.[8,9] Due to its biocompatibility, it has many dental and orthopaedic applications including development of implants with better integration.[10] It also can be used for the removal of heavy metals from contaminated soils, wastewater and fly ashes, thanks to its low water solubility, high thermal stability, possible high specific surface area and high sensibility to heavy metals.[11-13] Furthermore, with the surface acid-basicity as a function of $\mathrm{Ca} / \mathrm{P}$ molar ratio, it may be applied as catalyst support in reactions such as dry reforming of methane, ethanol electrooxidation and selective oxidation of alcohols.[14,15] However, because of the brittle nature of Ca-HA ceramics, composites starting from Ca-HA and another material such as CNTs are developed in order to enhance the physico-chemical and mechanical properties of Ca-HA and create beneficial synergy effects of these two individual initial materials. Research focused on CNT/Ca-HA composites continuously increases as shown previously.[16] Different methods have been developed for the synthesis of CNT/Ca-HA composites, including mechanical mixing, spray drying and chemical reaction.[16-19] This last one is usually based on either the growth of Ca-HA particles or layers on CNT surface, or the growth of CNTs on Ca-HA surfaces. Liao et al. studied the growth of Ca-HA on CNTs by coprecipitation of calcium phosphates in an aqueous suspension of CNTs.[20] Self-assembled Ca-HA on CNT surface was obtained. Xiao et al. investigated the in situ deposition of Ca-HA on CNT surface using the biomineralization method.[21] Firstly, CNT surface was treated by a phosphorylation step in order to promote the Ca-HA deposition. Then, these modified CNTs were immersed in a simulated body fluid (SBF) for the growth of Ca-HA on CNT surface. Mineral contents (Ca-HA) increased apparently with the contact time of CNTs in SBF and reached 65 wt.\% after $8 \mathrm{~h}$. The Ca-HA-functionalized CNT was found to have excellent biocompatibility and dispersion ability in aqueous system.[21] Using chemical reaction way, several results dedicated to the growth of $\mathrm{Ca}-\mathrm{HA}$ on CNT surface were reported in the literature.[16,19,22-26] On the other hand, work devoted to the formation of CNTs on the surface of $\mathrm{Ca}-\mathrm{HA}$ is rare. Lu et al. elaborated Ca-HA-based matrix containing iron and magnesium nanoparticles which catalysed the growth of CNTs from acetylene as carbon source. MWCNTs with a mean diameter of $40-60$ or $60-100 \mathrm{~nm}$ have been produced, using $\mathrm{Ca}-\mathrm{HA}$ and $\mathrm{Ca}-\mathrm{HA}$ foam, which were previously sintered at $1200{ }^{\circ} \mathrm{C} .[27,28]$

In this article, we investigated the growth of CNTs on the surface of a synthesized Ca-HA to generate CNT/Ca-HA composites, which are expected to have interesting properties for various applications in heterogeneous catalysis and energy fields. For the first time, methane was used as carbon source for the growth of CNTs.

\section{Materials and methods}

The chemicals used in this work had high purity (analytical grade). Ca-HA powder was synthesized from $\mathrm{Ca}(\mathrm{OH})_{2}$ suspension and orthophosphoric acid $\left(\mathrm{H}_{3} \mathrm{PO}_{4}, 75\right.$ wt.\%) by classical precipitation method. A mixture of $\mathrm{Ca}(\mathrm{OH})_{2}$ suspension and orthophosphoric acid having the theoretical molar $\mathrm{Ca} / \mathrm{P}$ ratio of 1.67 was kept under stirring $(600 \mathrm{rpm})$ at room temperature for $1 \mathrm{~h}$. The $\mathrm{pH}$ of the reaction mixture was adjusted around 10 using $\mathrm{NH}_{4} \mathrm{OH}$ solution. Then, the white precipitate was filtered and rinsed with water 
before drying overnight at $105^{\circ} \mathrm{C}$. This resulted to the formation of the powder Ca-HA, which had the specific surface area $\left(S_{B E T}\right)$ and the mean diameter $d_{50}$ of $7 \mathrm{~m}^{2} \mathrm{~g}^{-1}$ and $18.5 \mu \mathrm{m}$, respectively.

For the growth of CNTs, the synthesized Ca-HA was firstly functionalized by the deposition of well-dispersed nickel particles on its surface using the standard incipient wetness impregnation method.[29,30] An aqueous solution of $\mathrm{Ni}\left(\mathrm{NO}_{3}\right)_{2}$ was added dropwise to the $\mathrm{Ca}-\mathrm{HA}$ powder in order to get a consistent mixture. The concentration of $\mathrm{Ni}\left(\mathrm{NO}_{3}\right)_{2}$ solution was calculated in order to reach the desired nickel content in the final solid product (5 wt.\%). After the impregnation step, the mixture was dried at $105{ }^{\circ} \mathrm{C}$ and then fired in air at $500{ }^{\circ} \mathrm{C}$ for $2 \mathrm{~h}$ to convert nickel precursor into nickel oxides. Well-dispersed nickel particles are well known for accelerating the thermal decomposition of a hydrocarbon such as methane, being the carbon source for the formation of CNTs.

The growth of CNTs on the surface of nickel-doped Ca-HA was carried out using methane $\left(\mathrm{CH}_{4}\right)$ cracking reaction at high temperature. This reaction was carried out in a U-shaped fixed-bed quartz reactor (i.d. of $8 \mathrm{~mm}$ ). After filling the fixed-bed reactor with Ca-HA-based solid $(400 \mathrm{mg}$ ), the reactor was heated by a vertical cylindrical oven up to the desired temperature under nitrogen atmosphere. When the reactor reached the desired temperature, the cracking of methane started by feeding the reactor with 10 vol. $\%$ of $\mathrm{CH}_{4}$ diluted in argon gas. Gas products were analysed by micro-GC (A3000, Agilent). Parameters such as reaction temperature, reaction time and feeding flow rate were varied in order to evaluate their influence on the CNT production. The reaction temperature was varied between 400 and $700{ }^{\circ} \mathrm{C}$, the reaction time between 2 and $5 \mathrm{~h}$ and flow rate between 20 and $70 \mathrm{~mL} / \mathrm{min}$.

The determination of methane conversion was calculated as follows:

$$
\mathrm{CH}_{4} \text { conversion }(\%)=\frac{\left(\mathrm{CH}_{4}\right)_{\text {in }}-\left(\mathrm{CH}_{4}\right)_{\text {out }}}{\left(\mathrm{CH}_{4}\right)_{\text {in }}} \times 100
$$

Thermogravimetric analysis (TG) was carried out on a SDTQ600 analyzer (TA Instruments). The morphological and textural surface of the solid products was observed by scanning electron microscope (SEM) using a Philips XL30 ESEM apparatus (FEI Company). X-ray diffraction (XRD) data were collected using a Phillips Panalytical X'pert Pro MPD diffractometer with a $\mathrm{Cu} \mathrm{K} \mathrm{K}_{\alpha}(1.543 \AA)$ radiation source. Fourier transform infrared (FTIR) spectra were recorded on a Shimadzu FTIR 8400S spectrometer on ground solid powders.

\section{Results and discussion}

\subsection{Methane cracking over nickel-doped Ca-HA}

Figure 1 presents XRD and FTIR results of the initial Ca-HA powder. Ca-HA was found to be the main calcium phosphate obtained under the synthesis conditions used. In Figure 1(A), most of diffraction peaks could be attributed to calcium hydroxyapatite (JCPDS standard No. 01-072-1243).[31] In Figure 1(B), characteristic FTIR peaks of calcium hydroxyapatite could be found, in particular the peaks of phosphate group at $1076,1018,960,603,559 \mathrm{~cm}^{-1}$, and the peak of hydroxyl group at $633 \mathrm{~cm}^{-1}$.[31] Figures 2(A) and (B) report the conversion of $\mathrm{CH}_{4}$ over $\mathrm{Ca}-\mathrm{HA}$ and nickel-doped Ca-HA, respectively, at different temperatures, at a total flow rate equal to $70 \mathrm{~mL} / \mathrm{min}$, and after $4 \mathrm{~h}$ of time on stream. In the presence of the initial Ca-HA, methane cracking could slightly take place at $400{ }^{\circ} \mathrm{C}$, as previously observed.[32] The increase of the 

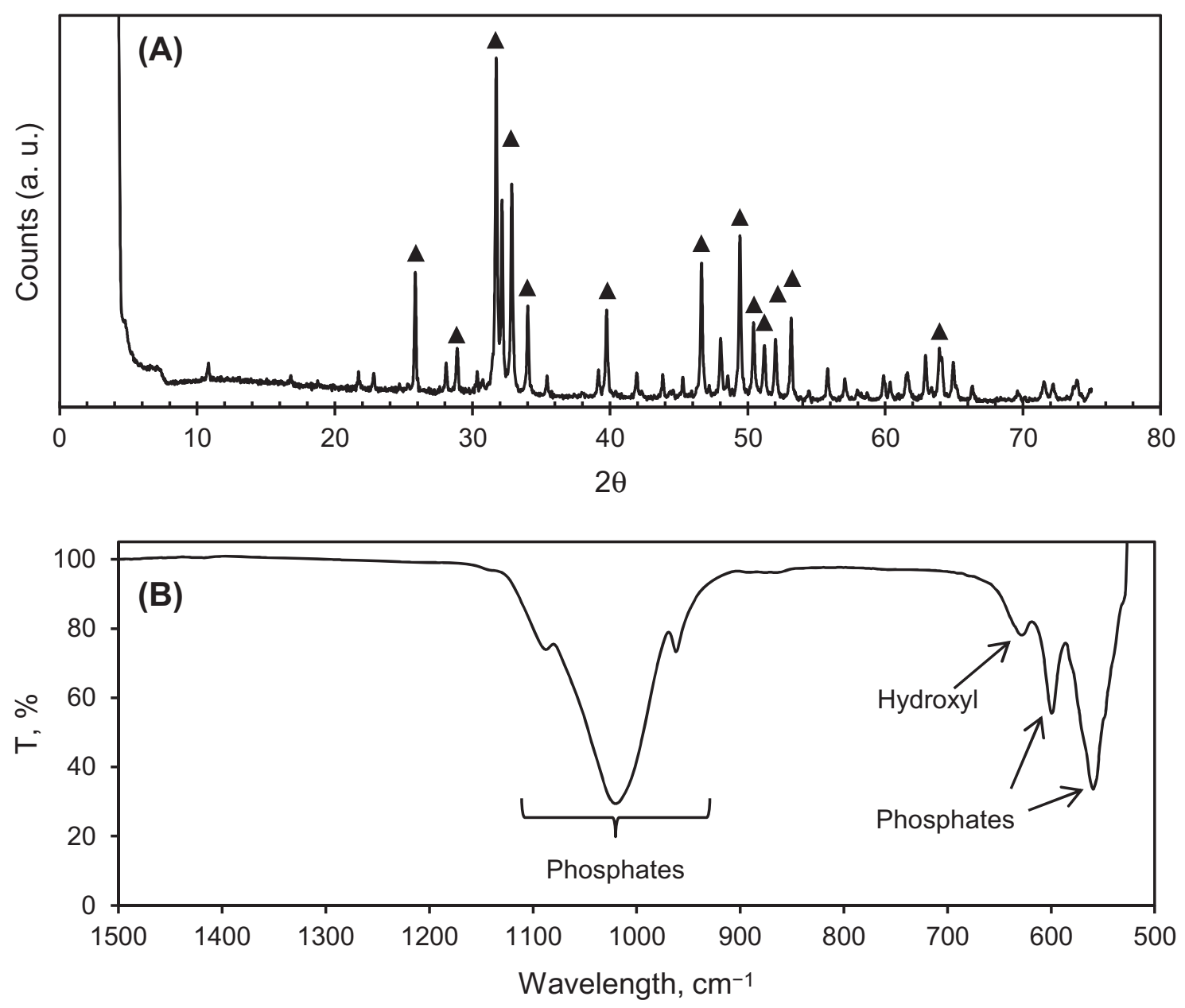

Figure 1. XRD pattern (A), and FTIR spectrum (B), of the initial Ca-HA obtained from Ca $(\mathrm{OH})_{2}$ and $\mathrm{H}_{3} \mathrm{PO}_{4}$ under the synthesis conditions used. *: Diffraction peaks of calcium hydroxyapatite (JCPDS Standard No. 01-072-1243).

temperature did not have significant effects on the cracking of methane and the methane conversion reached only $4 \%$ at $700{ }^{\circ} \mathrm{C}$. On the other hand, nickel-doped Ca-HA showed higher performance for the decomposition of methane compared to pure Ca-HA. At $700{ }^{\circ} \mathrm{C}$, a methane conversion of $40 \%$ was obtained. The high activity of nickel-doped $\mathrm{Ca}-\mathrm{HA}$ at $700{ }^{\circ} \mathrm{C}$ can be explained by the in situ reduction of nickel oxides under the experimental conditions used. In fact, the nickel-loaded Ca-HA used in this work was pretreated by air calcination. This step must lead to the formation of nickel oxides, which could not be active for the methane cracking reaction. The reduction of nickel oxides by gaseous hydrogen, which was formed from the thermal methane cracking, took place at high temperature to form nickel metal particles.[33,34] These catalyse better the methane cracking reaction, compared to nickel oxides. Under the present experimental conditions, hydrogen was the only gas product formed in significant quantity. A better methane conversion implies a higher production of CNTs. So, the temperature of $700{ }^{\circ} \mathrm{C}$ was then chosen for the next sections.

\subsection{Influence of the total feeding flow rate}

The influence of the feeding flow rates $(\mathrm{Q})$ on the methane cracking was investigated in the range of $20-70 \mathrm{~mL} \mathrm{~min}^{-1}$, keeping the same quantity of nickel-doped Ca-HA. 

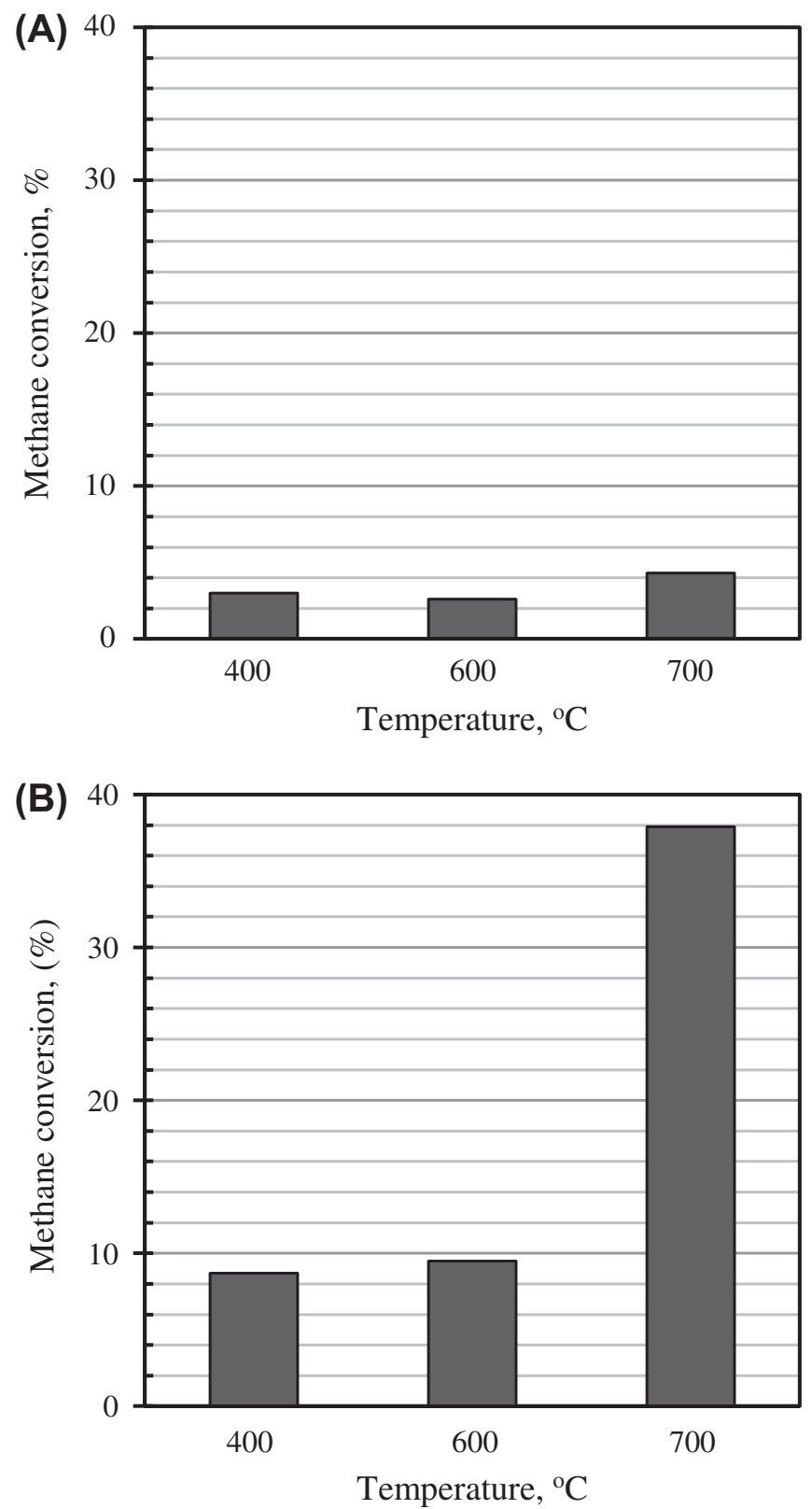

Figure 2. Methane conversion over (A), Ca-HA and (B), nickel-loaded Ca-HA; other conditions: atmospheric pressure, time on stream of $4 \mathrm{~h}$.

At the feeding flow rate of $20 \mathrm{~mL} / \mathrm{min}$, the methane cracking increased for the first three hours of reaction and then it decreased. As explained above, nickel oxides reduction probably took place at the beginning of the reaction to form metallic nickel particles. So, the methane cracking rate increased with the increase of metal fraction, which explains the increase of methane cracking rate for the first three hours of reaction. Then, methane cracking rate decreased because of the deposition of CNTs on the surface of Ca-HA which prevents the contact of methane with active nickel sites. When the total feeding flow rate increased to $50-70 \mathrm{~mL} \mathrm{~min}^{-1}$, methane cracking rate decreased between 1 and $5 \mathrm{~h}$ of time on stream explained also by CNT deposition. It is possible that the reduction of nickel oxides has ended within the first hour of time on stream at $50-70 \mathrm{~mL} \mathrm{~min}^{-1}$ (Figure 3). 


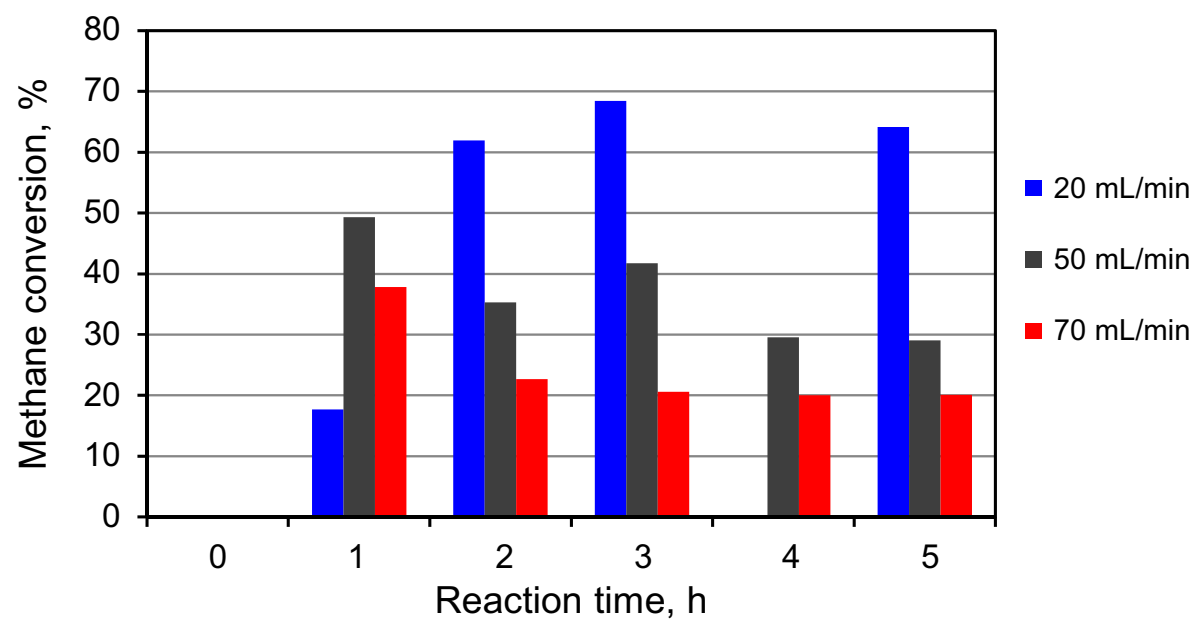

Figure 3. Methane conversion as a function of reaction time for the total feeding flow rate of $20-70 \mathrm{~mL} \mathrm{~min}{ }^{-1}$; other conditions: $700{ }^{\circ} \mathrm{C}$ and atmospheric pressure.

\subsection{TG analysis}

In order to quantify the carbon deposition on Ca-HA-based solids, TG analysis was performed under air atmosphere within 30 and $1000{ }^{\circ} \mathrm{C}$. Figure 4 presents TG curves of the synthesized $\mathrm{CNT} / \mathrm{Ca}-\mathrm{HA}$ composites. All three composites had similar thermal behaviour to each other. They had a strong weight loss between 450 and $650{ }^{\circ} \mathrm{C}$, which corresponds to the combustion of CNTs.[35] This combustion was total and could be expressed by the following equation:

$$
\mathrm{CNTs}+\mathrm{xO}_{2} \rightarrow \mathrm{xCO}_{2}
$$

Thus, the carbon deposited on Ca-HA matrix could be quantified from TG curves, which was around 8.3 wt.\%.

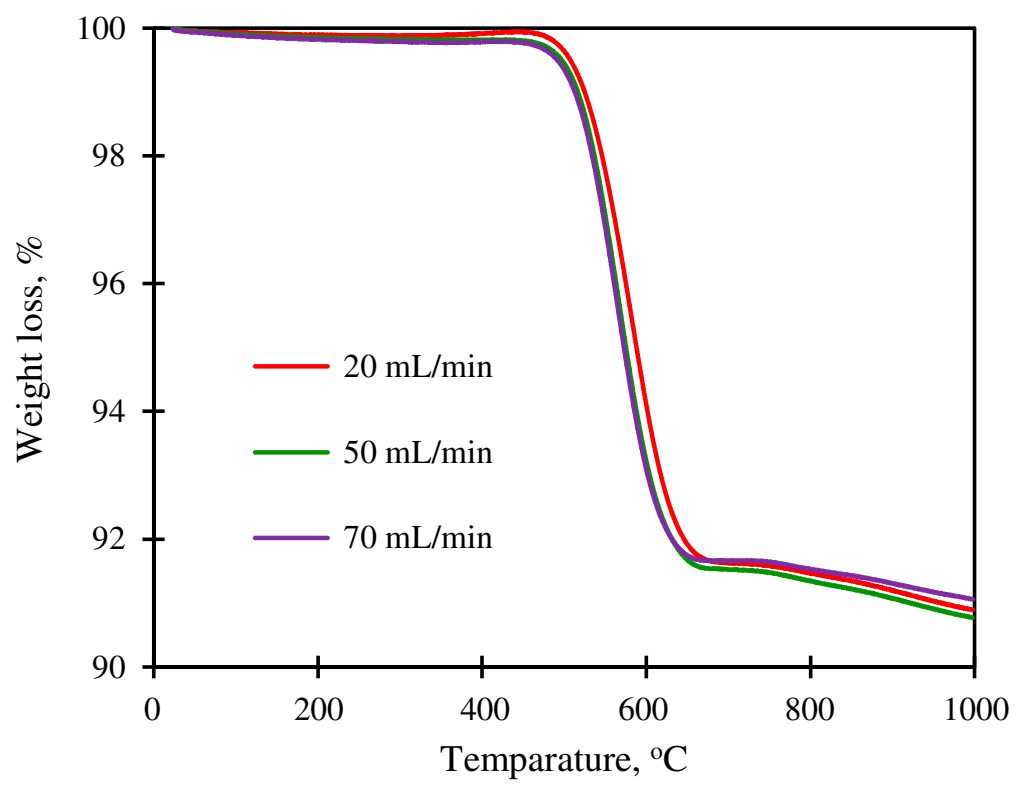

Figure 4. TG analysis of the powder after the methane cracking reaction at different flow rates; other conditions: $700{ }^{\circ} \mathrm{C}$, atmospheric pressure, $5 \mathrm{~h}$ of time on stream. 


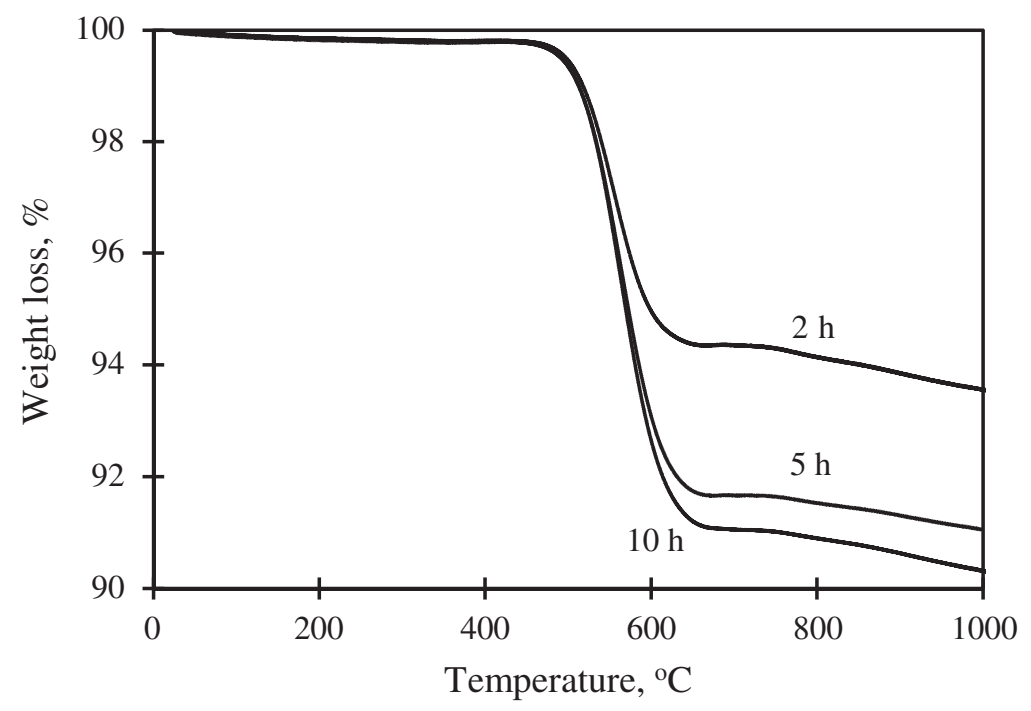

Figure 5. G analysis of the solids recovered after different times on stream; reaction conditions: $700{ }^{\circ} \mathrm{C}, 70 \mathrm{~mL} \mathrm{~min}{ }^{-1}, 400 \mathrm{mg}$ of Ni-doped Ca-HA, atmospheric pressure.

A slight weight loss was also observed between 740 and $1000{ }^{\circ} \mathrm{C}$ which can be attributed to the decarbonation of carbonated hydroxyapatite (CAP).[35] CAP is formed at low content when the synthesis reaction of Ca-HA from limestone and orthophosphoric acid is carried out under air atmosphere.[35]

Figure 5 illustrates TG analysis of the solids recovered after different methane cracking reaction times. As expected, the weight loss due to the combustion of CNTs, which ranged from 450 to $650{ }^{\circ} \mathrm{C}$, increased with the increase of methane cracking
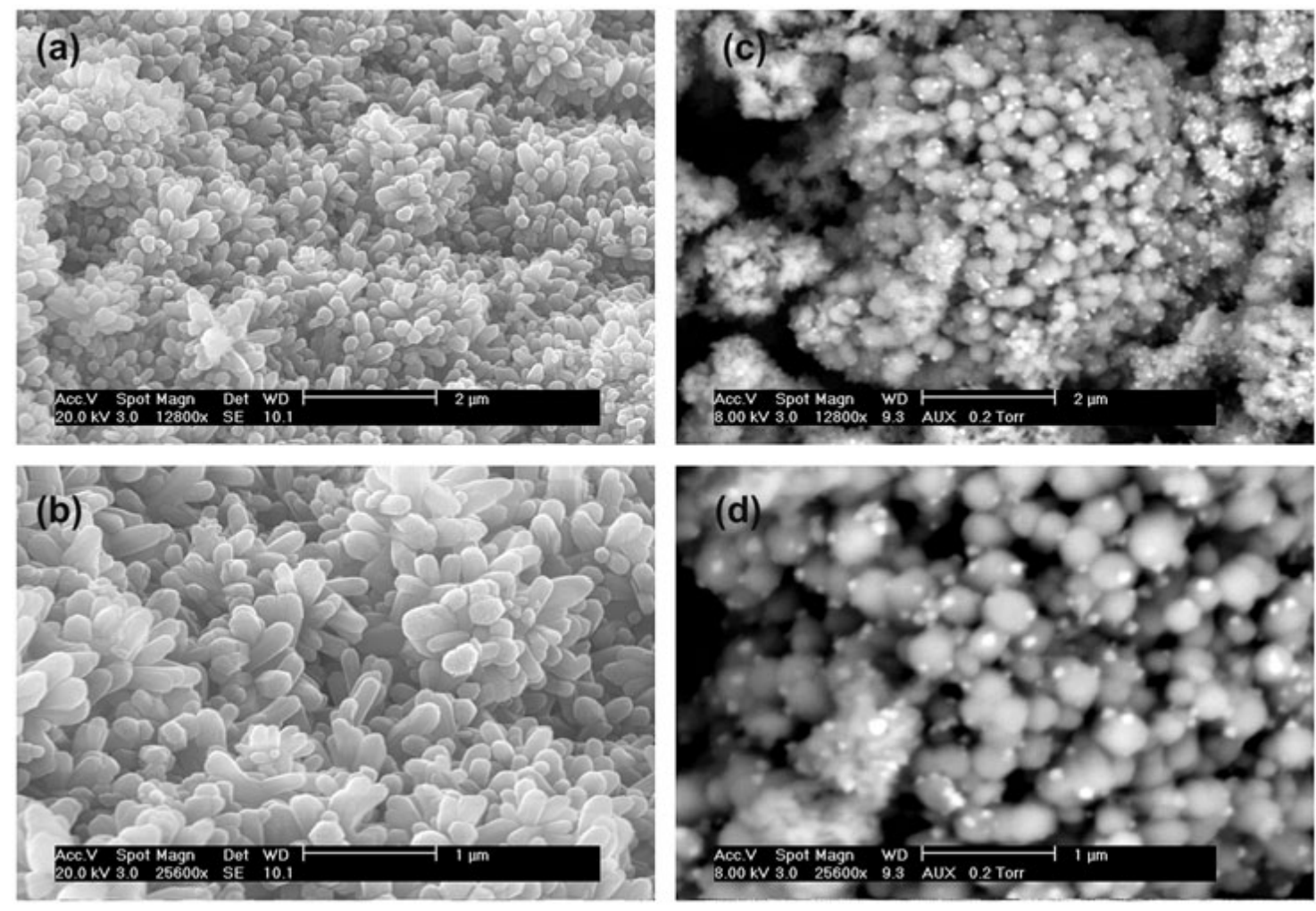

Figure 6. SEM images of the initial Ca-HA support (a, b) and the nickel-doped Ca-HA (c, d). 
reaction time. This weight loss reached 5.7, 8.3 and $8.9 \%$ after 2,5 and $10 \mathrm{~h}$ of time on stream. So the cracking reaction seemed to strongly slow down after $10 \mathrm{~h}$ of time on stream, probably due to the decrease of nickel particles available on the surface of Ca-HA.

\subsection{SEM characterization}

SEM analysis was performed in order to highlight the formation of nickel particles on Ca-HA surface and the growth of CNTs on nickel-doped Ca-HA. All samples were directly observed without any metallization step.
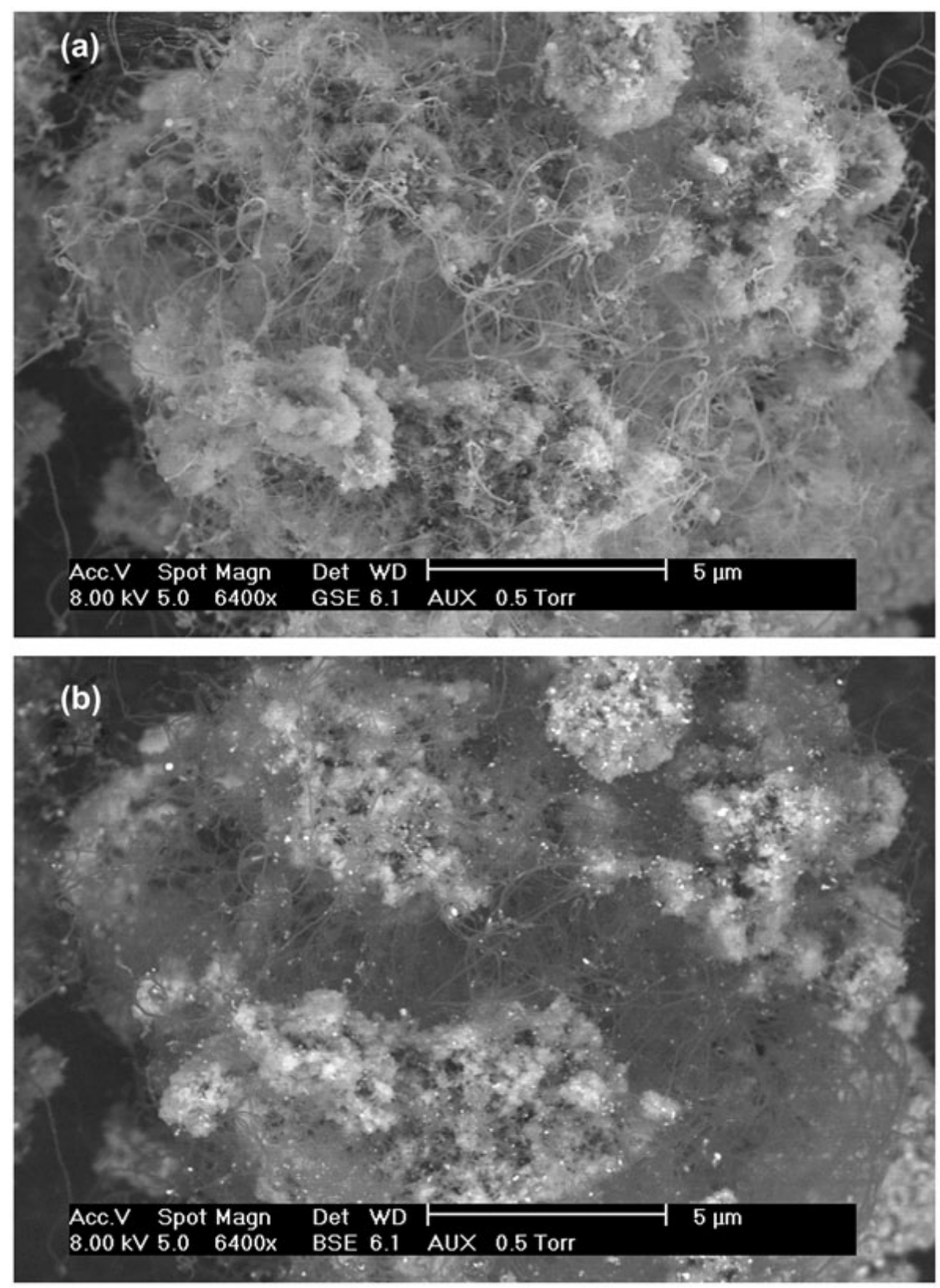

Figure 7. SEM images of CNTs/Ca-HA composite obtained after $5 \mathrm{~h}$ of reaction at $700{ }^{\circ} \mathrm{C}$, $20 \mathrm{~mL} \min ^{-1}, 400 \mathrm{mg}$ of Ni-doped Ca-HA, atmospheric pressure; (a) image obtained with a detector for secondary electrons (GSE); (b) image obtained with a detector for BSE. 
Figure 6 shows SEM images of the initial Ca-HA support and nickel-doped Ca-HA particles before methane cracking reaction. The initial Ca-HA support was composed of agglomerates of micrometric and nanometric particles (Figure 6(a) and (b)). Incipient wetness impregnation allowed the deposition of nanometric nickel particles on the surface of the Ca-HA support. The size of nickel particles, which were visible in SEM analysis, was estimated at around $20-70 \mathrm{~nm}$. These particles were well distributed on the surface of the Ca-HA support.

Figure 7 shows SEM images of CNT/Ca-HA composite obtained after $5 \mathrm{~h}$ of reaction at $700{ }^{\circ} \mathrm{C}$ with the feeding flow rate of $20 \mathrm{~mL} \mathrm{~min}^{-1}$. Using a detector for gaseous secondary electrons (GSE), images of high tomography quality were obtained as illustrated on Figure 7(a). CNTs could be easily observed on the surface of nickeldoped Ca-HA but this observation mode did not allow highlighting the presence of
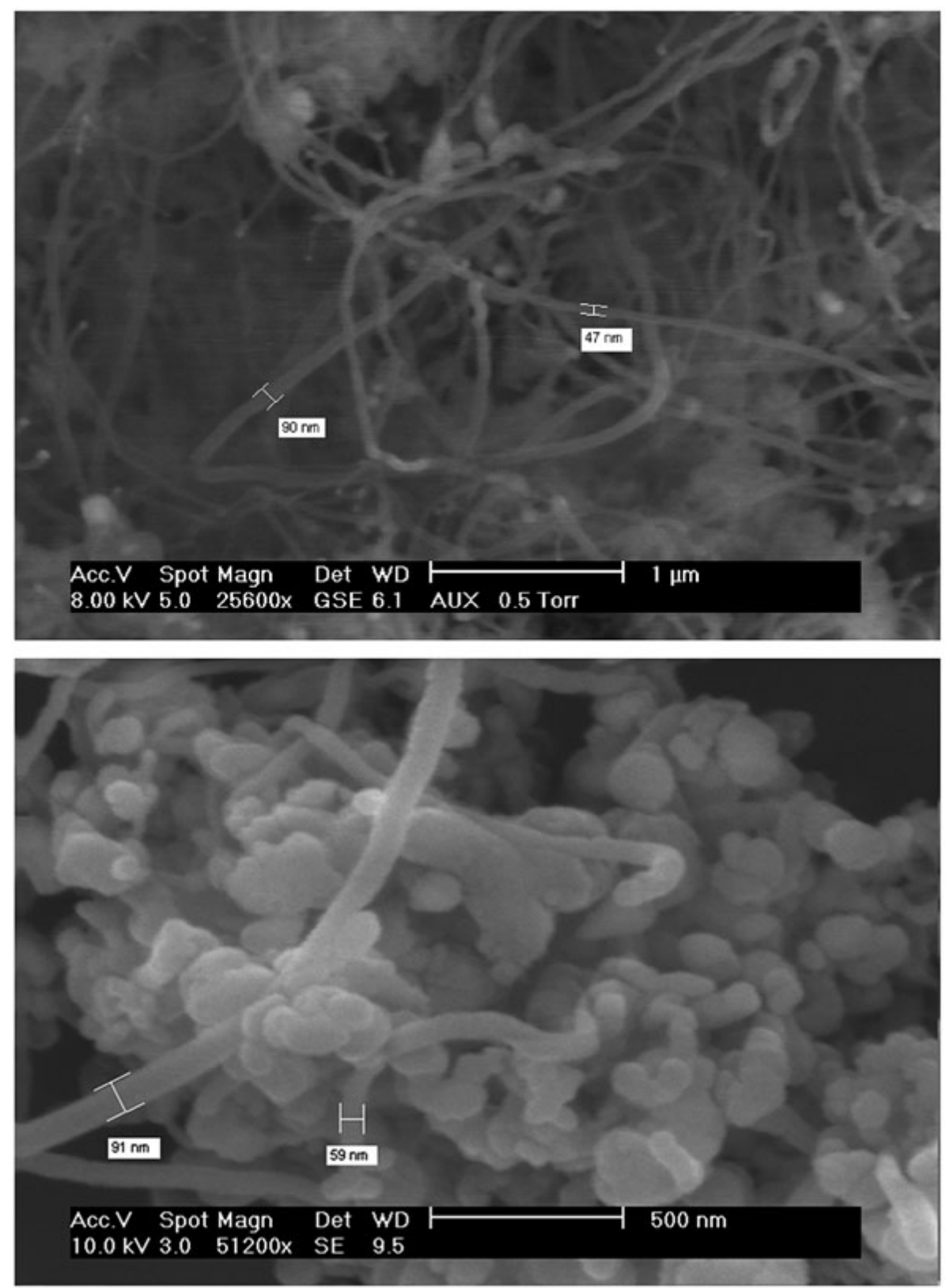

Figure 8. Illustration of CNT size, obtained at $700{ }^{\circ} \mathrm{C}$ under atmospheric pressure. 
nickel particles. Using a detector for back-scattered electrons (BSE), image of high chemical contrast was obtained which evidenced nickel particles, which had the highest chemical contrast compared to other elements present in CNT/Ca-HA composite. So, these two observation modes allowed distinguishing both CNTs and nickel particles. We can see that the growth of CNTs was not ordered and its formation was strongly linked with the presence of nickel particles. Nickel particles, which catalysed the growth of CNTs, conditioned the external diameter of CNTs, as illustrated on Figure 8. It varied from about 30 to $100 \mathrm{~nm}$.

Figures 9-11 are SEM images of CNT/Ca-HA composites obtained at different reaction times at $700{ }^{\circ} \mathrm{C}$ under atmospheric pressure. According to TG analysis (Figure 5), CNT content increased with the increase of the reaction time. In all cases,
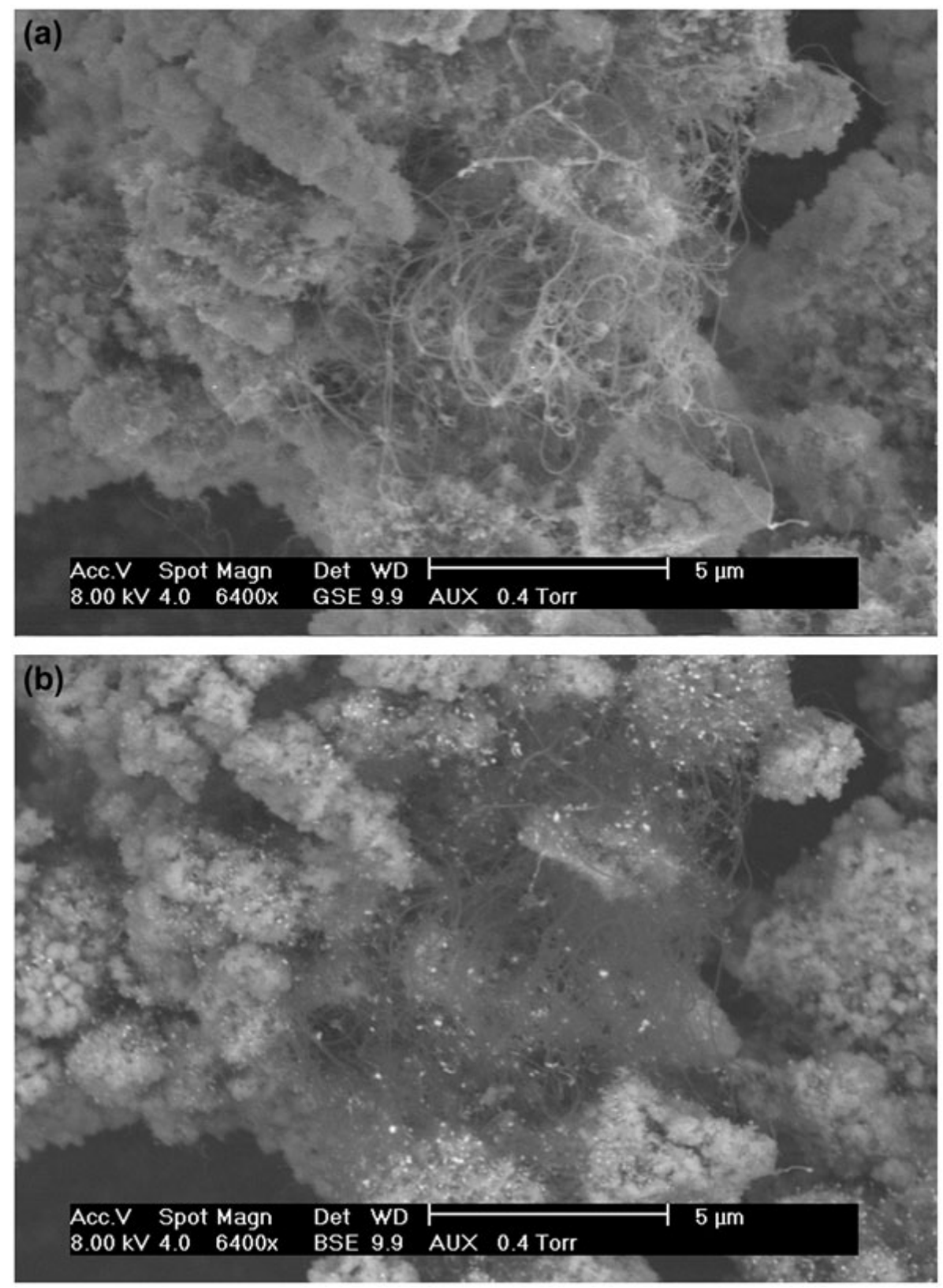

Figure 9. SEM images of CNTs/Ca-HA composite obtained after $2 \mathrm{~h}$ of reaction at $700{ }^{\circ} \mathrm{C}$,

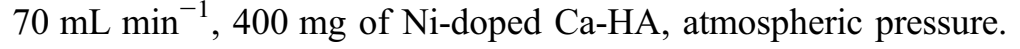



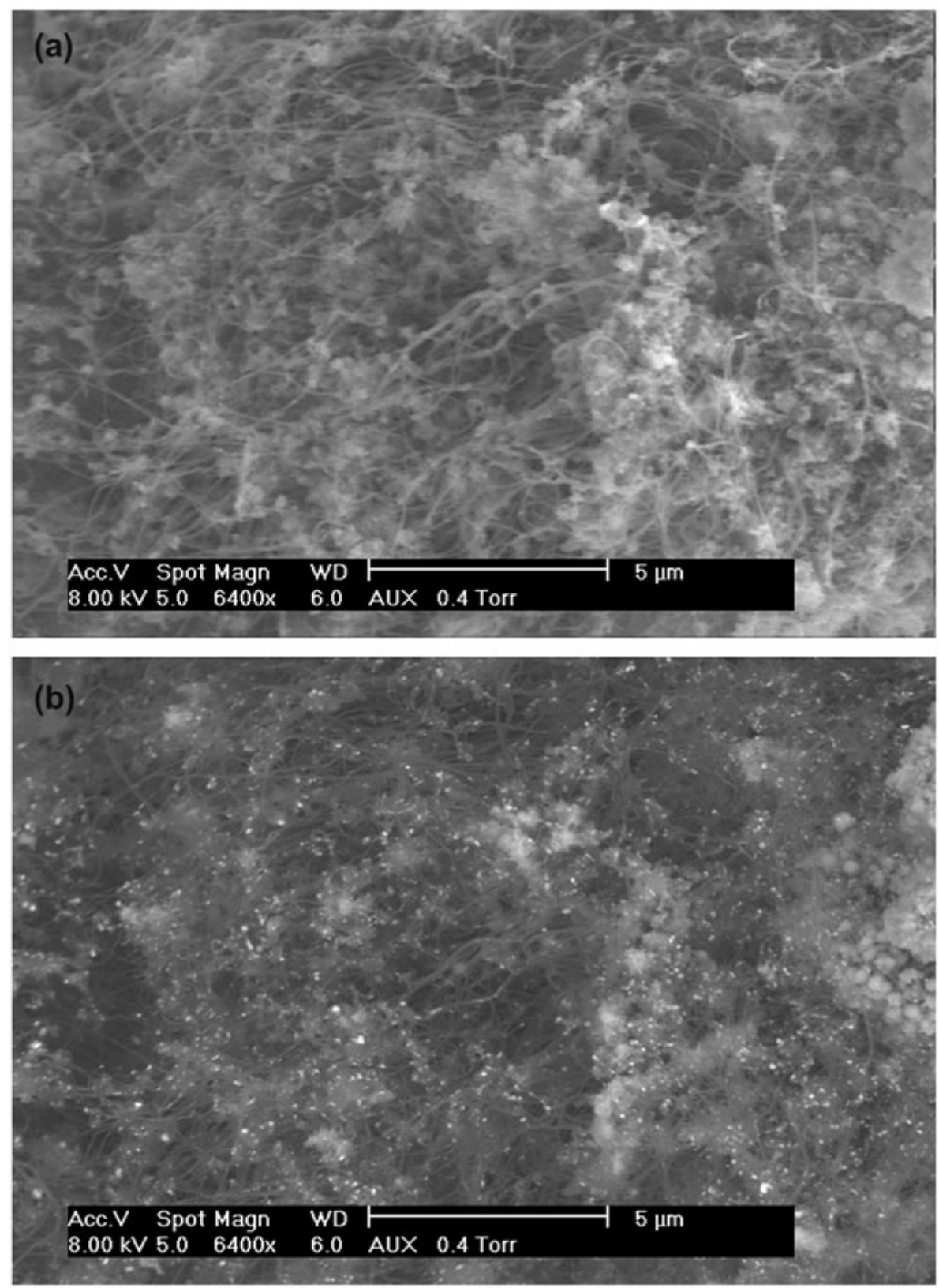

Figure 10. SEM images of CNTs/Ca-HA composite obtained after $5 \mathrm{~h}$ of reaction at $700{ }^{\circ} \mathrm{C}$,

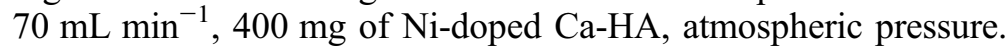

GSE and BSE images highlighted the formation of CNTs and the presence of nickel particles on the surface of Ca-HA.

\subsection{Specific surface area}

Specific surface area of CNT/Ca-HA products was measured by BET method. Despite the various CNT content (5-9 wt.\%), the value of BET surface was almost similar to each other (about 7-9 $\mathrm{m}^{2} \mathrm{~g}^{-1}$ ). In fact, CNTs may have various specific surface areas as a function of its internal and external diameter.[36] The theoretical specific surface area of CNTs having the external diameter of $8-28 \mathrm{~nm}$ is between 400 and $70 \mathrm{~m}^{2} \mathrm{~g}^{-1}$.[36] For higher external diameter as observed for our composites, the specific surface area of these CNTs must be lower than $70 \mathrm{~m}^{2} \mathrm{~g}^{-1}$. So, the presence of 

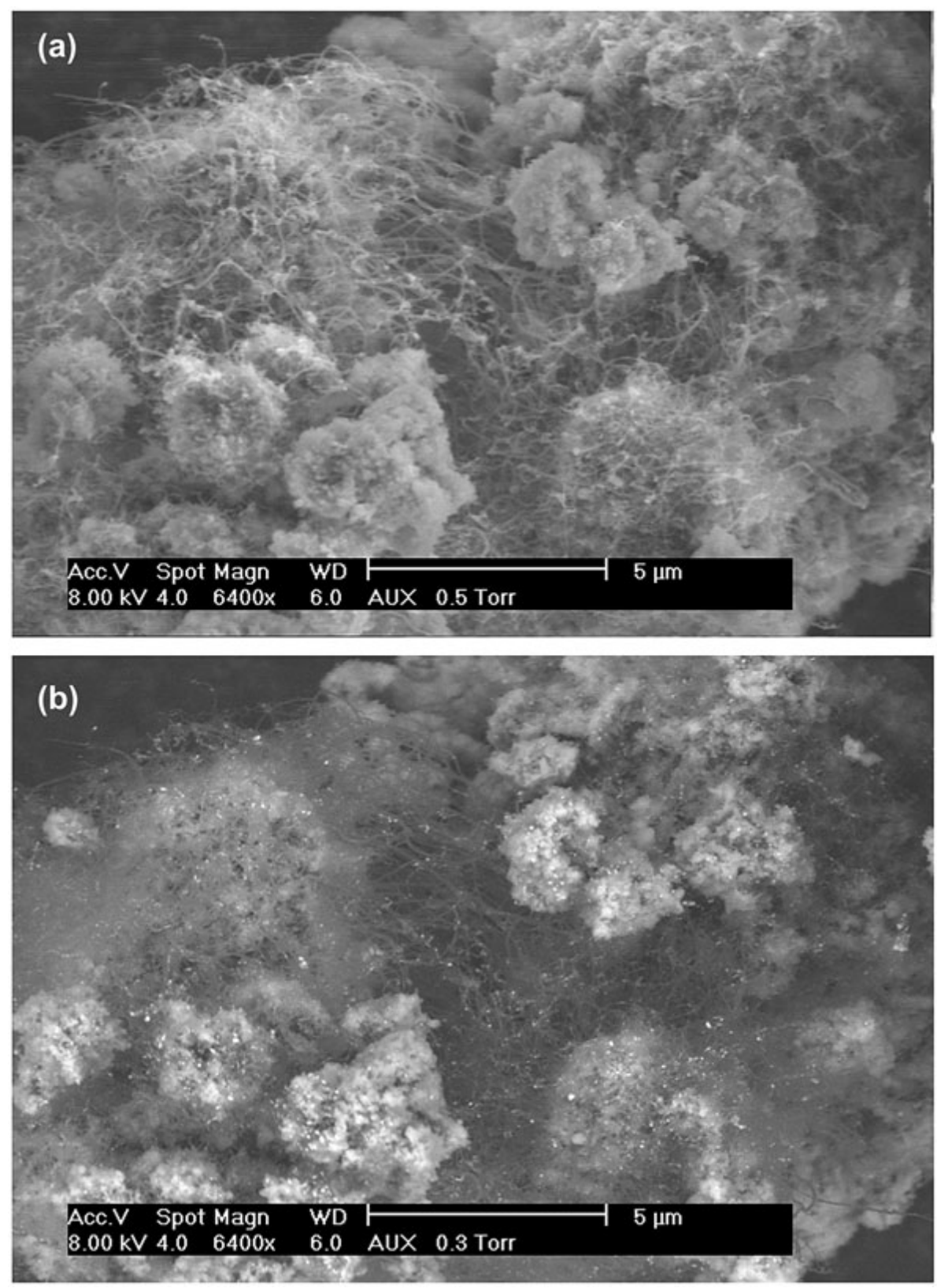

Figure 11. SEM images of CNTs/Ca-HA composite obtained after $10 \mathrm{~h}$ of reaction at $700{ }^{\circ} \mathrm{C}$,

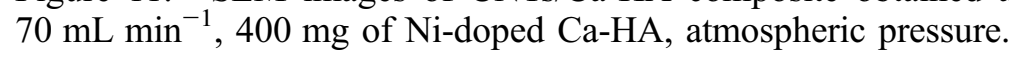

5-9 wt.\% of such CNTs in the composites must not change strongly their specific surface area, which explained the results obtained for our CNT/Ca-HA products.

\subsection{Discussion}

As mentioned in Section 1, most of research focused on the deposition of Ca-HA on the surface of CNTs. Only a few works was devoted to the growth of CNTs on Ca-HA surface. Regarding the results obtained by Lu et al. wherein nano-FeMg-Ca-HA crystals catalysed the formation of CNTs from the decomposition of $\mathrm{C}_{2} \mathrm{H}_{2}$, CNTs with a mean diameter of 40-60 nm.[27] The content of CNTs could reach up to around $18 \mathrm{wt} . \%$. When Ca-HA-based foam, which incorporated also iron and magnesium in its structure, 
was sintered at $1200{ }^{\circ} \mathrm{C}$ before CNTs growth, the content of CNTs formed was only less than $3 \mathrm{wt} . \%$ with a mean diameter of $60-100 \mathrm{~nm}$.[28] Using microwave plasma enhanced chemical vapour deposition (MPECVD), El-Shazly et al. were successful in the growth of CNTs with a mean diameter of 30-70 nm on the surface of nickel-doped Ca-HA.[37] No communication on the content of nickel and CNTs was reported in this work.[37] The results obtained in the present work allowed confirming the feasibility for growing CNTs on Ca-HA surface, catalysed by Ni nanoparticles.

The localization of active metals particles ( $\mathrm{Ni}, \mathrm{Fe}, \mathrm{Mg}$ ) in as-synthesized $\mathrm{CNT} /$ Ca-HA composites seems to be important. In fact, CNT/Ca-HA composites obtained from the present work contained up to $5 \mathrm{wt} . \%$ of nickel particles. It is possible that nickel particles were still located on the surface of Ca-HA and covered by carbonaceous species. It is also possible that they were detached from Ca-HA surface. For instant, any effort was done on this task. Understanding the fate of nickel particles in final CNT/Ca-HA composites is necessary for its efficient use.

\section{Conclusions}

CNT/Ca-HA composites were successfully synthesized by the methane cracking reaction over nickel-doped Ca-HA (5 wt.\%). The temperature of $700{ }^{\circ} \mathrm{C}$ seemed to be crucial for the efficient decomposition of methane. This thermal catalytic decomposition led to the formation of hydrogen as the only main gas product and the growth of CNTs on the surface of nickel-doped Ca-HA. After $10 \mathrm{~h}$ of reaction, the CNT content reached $8.9 \mathrm{wt} . \%$ and the methane cracking reaction still took place. The results obtained in this work represent a promising contribution to the research field related to the growth of CNTs on Ca-HA surface.

Ongoing research will focus on the structural characterization such as HRTEM and the use of CNT/Ca-HA composites in catalytic reactions for energy carrier products.

\section{Acknowledgements}

The authors gratefully acknowledge colleagues at RAPSODEE Center for technical help.

\section{References}

[1] Wang K, Chizari K, Liu Y, et al. Catalytic synthesis of a high aspect ratio carbon nanotubes bridging carbon felt composite with improved electrical conductivity and effective surface area. Appl. Catal., A. 2011;392:238-247.

[2] Bazargan A, McKay G. A review-synthesis of carbon nanotubes from plastic wastes. Chem. Eng. J. 2012;195-196:377-391.

[3] Deneuve A, Wang K, Janowska I, et al. Bucky paper with improved mechanical stability made from vertically aligned carbon nanotubes for desulfurization process. Appl. Catal., A. 2011;400:230-237.

[4] Nhut JM, Pesant L, Tessonnier J-P, et al. Mesoporous carbon nanotubes for use as support in catalysis and as nanosized reactors for one-dimensional inorganic material synthesis. Appl. Catal., A. 2003;254:345-363.

[5] Ghiazza M, Vietti G, Fenoglio I. 8-Carbon nanotubes: properties, applications and toxicity. In: Njuguna J, Pielichowski K, Zhu H, editors. Health and Environmental Safety of Nanomaterials. Elsevier 2014, p. 147-174.

[6] Jiang H, Lee PS, Li C. 3D carbon based nanostructures for advanced supercapacitors. Energy Environ. Sci. 2013;6:41-53. 
[7] Li T, Lee J-H, Wang R, et al. Enhancement of heat transfer for thermal energy storage application using stearic acid nanocomposite with multi-walled carbon nanotubes. Energy. 2013;55:752-761.

[8] Rodríguez-Lorenzo LM, Vallet-Regí M, Ferreira JMF. Fabrication of hydroxyapatite bodies by uniaxial pressing from a precipitated powder. Biomaterials. 2001;22:583-588.

[9] Pham Minh D, Lyczko N, Sebei H, Nzihou A, Sharrock P. Synthesis of calcium hydroxyapatite from calcium carbonate and different orthophosphate sources: a comparative study. Mater. Sci. Eng., B. 2012;177:1080-1089.

[10] Habraken WJEM, Wolke JGC, Jansen JA. Ceramic composites as matrices and scaffolds for drug delivery in tissue engineering. Adv. Drug Deliv. Rev. 2007;59:234-248.

[11] Baillez S, Nzihou A, Bernache-Assolant D, Champion E, Sharrock P. Removal of aqueous lead ions by hydroxyapatites: equilibria and kinetic processes. J. Hazar. Mater. 2007;139: 443-446.

[12] Pham Minh D, Sebei H, Nzihou A, Sharrock P. Apatitic calcium phosphates: synthesis, characterization and reactivity in the removal of lead(II) from aqueous solution. Chem. Eng. J. 2012;198-199:180-190.

[13] Pham Minh D, Rio S, Sharrock P, et al. Hydroxyapatite starting from calcium carbonate and orthophosphoric acid: synthesis, characterization, and applications. J. Mater. Sci. 2014;49:4261-4269.

[14] Boukha Z, Kacimi M, Pereira MFR, Faria JL, Figueiredo JL, Ziyad M. Methane dry reforming on Ni loaded hydroxyapatite and fluoroapatite. Appl. Catal., A. 2007;317:299-309.

[15] Cui Q, Chao S, Bai Z, Yan H, Wang K, Yang L. Based on a new support for synthesis of highly efficient palladium/hydroxyapatite catalyst for ethanol electrooxidation. Electrochim. Acta. 2014;132:31-36.

[16] Lahiri D, Ghosh S, Agarwal A. Carbon nanotube reinforced hydroxyapatite composite for orthopedic application: a review. Mater. Sci. Eng., C. 2012;32:1727-1758.

[17] Mukherjee S, Kundu B, Sen S, Chanda A. Improved properties of hydroxyapatite-carbon nanotube biocomposite: mechanical, invitrobioactivity and biological studies. Ceram. Int. 2014;40:5635-5643.

[18] Balani K, Anderson R, Laha T, et al. Plasma-sprayed carbon nanotube reinforced hydroxyapatite coatings and their interaction with human osteoblasts in vitro. Biomaterials. 2007;28:618-624.

[19] Kosma V, Tsoufis T, Koliou T, et al. Fibrous hydroxyapatite-carbon nanotube composites by chemical vapor deposition: in situ fabrication, structural and morphological characterization. Mater. Sci. Eng., B. 2013;178:457-464.

[20] Liao S, Xu G, Wang W, et al. Self-assembly of nano-hydroxyapatite on multi-walled carbon nanotubes. Acta Biomater. 2007;3:669-675.

[21] Xiao Y, Gong T, Zhou S. The functionalization of multi-walled carbon nanotubes by in situ deposition of hydroxyapatite. Biomaterials. 2010;31:5182-5190.

[22] Niu L, Kua H, Chua DHC. Bonelike apatite formation utilizing carbon nanotubes as template. Langmuir. 2010;26:4069-4073.

[23] Irineu JAF, Marsi TCO, Santos TG, Corat EJ, Marciano FR, Lobo AO. Efficient method to produce biomineralizated nanohydroxyapatite/vertically aligned multiwalled carbon nanotube scaffolds. Mater. Lett. 2012;79:166-169.

[24] Aryal S, Bhattarai SR, Remant Bahadur KC, et al. Carbon nanotubes assisted biomimetic synthesis of hydroxyapatite from simulated body fluid. Mater. Sci. Eng., A. 2006;426: 202-207.

[25] Akasaka T, Watari F, Sato Y, Tohji K. Apatite formation on carbon nanotubes. Mater. Sci. Eng., C. 2006;26:675-678.

[26] Aryal S, Remant Bahadur KC, Dharmaraj N, Kim KW, Kim HY. Synthesis and characterization of hydroxyapatite using carbon nanotubes as a nano-matrix. Scr. Mater. 2006;54: $131-135$.

[27] Lu XY, Zhang NY, Wei L, et al. Fabrication of carbon nanotubes/hydroxyapatite nanocomposites via an in situ process. Appl. Surf. Sci. 2012;262:110-113.

[28] Lu XY, Qiu T, Wang XF, et al. Preparation of foam-like carbon nanotubes/hydroxyapatite composite scaffolds with superparamagnetic properties. Appl. Surf. Sci. 2012;262:227-230. 
[29] Galera Martínez M, Pham Minh D, Weiss-Hortala E, Weiss-Hortala E, Nzihou A, Sharrock P. Synthesis, characterization, and thermo-mechanical properties of copper-loaded apatitic calcium phosphates. Compos. Interfaces. 2013;20:647-660.

[30] Pham Minh D, Aubert G, Gallezot P, Besson M. Degradation of olive oil mill effluents by catalytic wet air oxidation: 2-Oxidation of p-hydroxyphenylacetic and p-hydroxybenzoic acids over Pt and Ru supported catalysts. Appl. Catal., B. 2007;73:236-246.

[31] Pham Minh D, Tran ND, A Nzihou, Sharrock P. Carbonate-containing apatite (CAP) synthesis under moderate conditions starting from calcium carbonate and orthophosphoric acid. Mater. Sci. Eng., C 2013;33:2971-2980.

[32] Monnerat B, Kiwi-Minsker L, Renken A. Hydrogen production by catalytic cracking of methane over nickel gauze under periodic reactor operation. Chem. Eng. Sci. 2001;56: 633-639.

[33] Clause O, Bonneviot L, Che M. Effect of the preparation method on the thermal stability of silica-supported nickel oxide as studied by EXAFS and TPR techniques. J. Catal. 1992;138:195-205.

[34] Al-Dalama K, Stanislaus A. Temperature programmed reduction of $\mathrm{SiO}_{2}-\mathrm{Al}_{2} \mathrm{O}_{3}$ supported $\mathrm{Ni}$, Mo and NiMo catalysts prepared with EDTA. Thermochim. Acta. 2011;520:67-74.

[35] Mahajan A, Kingon A, Kukovecz A, Konya Z, Vilarinho PM. Studies on thermal decomposition of multiwall carbon nanotubes under different atmospheres. Mater. Lett. 2013;90:165-168.

[36] Peigney A, Laurent C, Flahaut E, Bacsa RR, Rousset A. Specific surface area of carbon nanotubes and bundles of carbon nanotubes. Carbon. 2001;39:507-514.

[37] El-Shazly MD, Hannora A, Mansurov Z, Beall GW. Direct growth of carbon nanotubes on hydroxyapatite using MPECVD. Mater. Chem. Phys. 2012;132:119-124. 